\title{
Development of new core competencies for Taiwanese Emergency Medical Technicians
}

\author{
Yu-Tung Chang ${ }^{1,2}$ \\ Kuang-Chau Tsai \\ Brett Williams ${ }^{1,3}$ \\ 'Department of Community \\ Emergency Health and Paramedic \\ Practice, Faculty of Medicine, \\ Nursing and Health Sciences, Monash \\ University, Frankston, VIC, Australia; \\ ${ }^{2}$ Department of Emergency Medicine, \\ Far Eastern Memorial Hospital, New \\ Taipei City, Taiwan; ${ }^{3}$ Division of \\ Paramedicine, University of Tasmania, \\ Hobart, TAS, Australia
}

This article was published in the following Dove Press journal: Advances in Medical Education and Practice

\begin{abstract}
Objectives: Core competencies are considered the foundation for establishing Emergency Medical Technician (EMT) and paramedic curricula, and for ensuring performance standards in the delivery of prehospital care. This study surveyed EMT instructors and medical directors to identify the most desirable core competencies for all levels of EMTs in Taiwan.
\end{abstract}

Methods: A principal components analysis with Varimax rotation was conducted. An online questionnaire was distributed to obtain perspectives of EMT instructors and medical directors on the most desirable core competencies for EMTs. The target population was EMT training-course instructors and medical directors of fire departments in Taiwan. The questionnaire comprised 61 competency items, and multiple-choice and open-ended questions were used to obtain respondents' perspectives of the Taiwanese EMT training and education system.

Results: The results identified three factors at EMT-1 and EMT-2 levels and five factors at the EMT-Paramedic level. The factors for EMT-1 and EMT-2 were similar, and those for EMTParamedics identified further comprehensive competence perspectives. The key factors that appear to influence the development of the Taiwanese Emergency Medical Services (EMS) education system are the attitude of authorities, the licensure system, and legislation.

Conclusion: The findings present new core competencies for the Taiwanese EMT system and provide capacity to redesign curricula and reconsider roles for EMT-1 and EMT-2 technicians. At the EMT-Paramedic level, the findings demonstrate the importance of incorporating competency standards in the current skills-based curriculum. Moreover, the core-competencies gap that exists between Taiwanese EMT-1s, EMT-2s, and EMT-Paramedics and internationally recognized core competencies needs to be addressed. By identifying the key factors that potentially impact the development of the EMS education system, such as the attitude of authorities, the licensure system, and legislation, these findings will inform future curricula design in Taiwan.

Keywords: EMT, paramedics, core competencies, curriculum standards

\section{Introduction}

The Emergency Medical Services (EMS) Act and Emergency Medical Technician (EMT) Administration Regulation were first enacted in Taiwan in the late 1990s. They represent the foundation of the Taiwanese EMS operating and training system, together with the fire departments who have been the main emergency healthcare provider within the EMS system. ${ }^{1,2}$ There are three levels of EMT in Taiwan - EMT-1, EMT-2, and EMT-Paramedic (EMT-P), training for which has traditionally been based on skills-focused standards. ${ }^{1,2}$ Hours spent in training range from 40 hours for EMT- $1 \mathrm{~s}$ to 1,280 hours at the EMT-P level.

Since the establishment of the EMS system, only medical doctors and nurses were authorized to instruct EMTs in basic medical knowledge and first aid skills. In 1999,
Correspondence: Brett Williams Health and Paramedic Practice, School of Primary and Allied Health Care, Faculty of Medicine, Nursing and Health Sciences, Monash University, Level 2, Building $\mathrm{H}$,

Peninsula Campus, McMahons Road Frankston, VIC 3199, Australia

Tel +6I 399044283

Fax +6I 410980583

Email brett.williams@monash.edu 
the first EMT instructor training course was conducted by the National Fire Agency (NFA) and the Bureau of Military Medical Affairs which brought the EMT training system within the remit of the NFA. ${ }^{1}$ In 2015 , the number of NFAbased EMTs was 12,420 (EMT-1 10.4\%; EMT-2 80.5\%; and EMT-P 9.1\%) of whom 788 were training assistants and 541 were course instructors. ${ }^{1}$ Although the total number of EMT instructors has increased in recent years, quality control and management of instructors have not been formally regulated. ${ }^{2}$

Core competency can be defined as the generic skills, knowledge, and attitude of a graduate student in the context of professional development, resulting from occupational training or university education. ${ }^{3}$ Previous research has highlighted the importance of core competencies as the foundation for establishing EMT and paramedic curricula and delivering high-quality prehospital care. ${ }^{3,4}$ A review of the literature and documents of official curriculum standards for EMT/paramedic education and training worldwide revealed that core competencies have been identified and are welldefined by the regulating authorities in most countries ${ }^{2,3,5-12}$ (see Table S1). In Taiwan, however, no published literature or authorized curriculum documents have defined EMT core competencies. Current competencies relate only to the contents of the skills-based curriculum, which focuses on EMT training to develop "technicians" rather than "emergency healthcare clinicians".

Therefore, the aim of this study was to survey EMT instructors and medical directors across Taiwan to identify the perceived most desirable core competencies for all levels of EMT. Our results will inform future EMT curriculum standards and curricula in Taiwan, and build an evidence base that can be used to inform the development of a modern Taiwanese EMS education system that is fit for the purpose.

\section{Methods}

\section{Design}

The study design used a principal components analysis (PCA) with Varimax rotation.

\section{Participants}

Questionnaires were distributed to EMT instructors and medical directors to obtain their perspectives of the most desirable core competencies for all levels of EMT in Taiwan. The EMT Administration Regulation stipulates that only medical doctors, registered nurses, and EMT-Ps with at least 3 years' experience in emergency healthcare can qualify as instructors. ${ }^{2}$ Based on information from the NFA, there are currently 541 EMT instructors in Taiwan and 60 medical directors within each region. ${ }^{1}$ The total estimated number of participants was, therefore, $600 .^{1}$

\section{Instrumentation}

This questionnaire comprised three sections. The first section collected demographic information on participants including age, gender, working region, and clinical and educational experience (year); the second section contained 61 core competencies extracted from a review of the literature and official documents such as EMT competency standards with regard to desirable attributes for paramedics. Participants rated each competency on a Likert scale (where $1=$ the least important competence and $10=$ the most important competence) based on the necessity and importance of each core competency at the three EMT levels. In the third section, multiple-choice and open-ended questions were used to obtain the participants' opinions on the current and future EMS training systems and the environment in Taiwan.

When designing the questionnaire, it was important to establish the core competency items in Section 2. Content was based on previous research in the UK and Australia on core competencies of EMTs and paramedics for the purpose of establishing a blueprint for future EMT and paramedic education and curricula., ${ }^{3,12}$ A consensus on the EMS educators opinions and scientific methodologies derived from these studies was used as the foundation for the questionnaire, and resources for formulating core competency items included competency documents and curricula standards from Australia, USA, UK, Ireland, Canada, South Africa, and Taiwan. ${ }^{2,5-10}$ Pooling these resources together to extract and summarize core competencies from international documents and curricula standards yielded more than 100 items. Following consultation with EMS educators in Australia and Taiwan, more than 40 items that related to specific skills or procedures, or represented similar competencies, were removed or combined. This process reduced the core competency items for the questionnaire to 61 , and an additional section included multiple-choice and open-ended questions to obtain the perspectives of the participants on EMT training and education in Taiwan.

\section{Procedure}

To ensure the confidentiality of participants, an official letter was sent to 20 fire departments inviting the staff to participate in the study and assist with the distribution of questionnaires to regional EMT instructors and medical directors. Fifteen fire departments agreed to participate in the study and distribute questionnaires to the target population. The 
Qualtrics Insight Platform was used to design the layout of the questionnaire, create a participant information letter, and to generate linkage for distribution. As this was an online questionnaire, the informed consent page was the first page of this questionnaire such that participants could provide their consent by pressing the "Accept" button and continue to answer this questionnaire. All participants had the right to leave this survey at any point before they were sent the results. The study was approved by the Ethics Committee of Monash University in late 2016, and approval from the Ethics Committee of the Far Eastern Memorial Hospital in Taiwan was granted in March 2017.

\section{Statistical analysis}

SPSS v.22 was used to store and analyze the data generated by the questionnaire. Data analysis data comprised three parts: descriptive analysis, PCA, and text analysis. Descriptive analysis was used to present the demographic information of participants, including age, gender, working region, and clinical and teaching experiences (in year), by mean and percentage. The 61 core competencies scores for the three EMT levels were analyzed using descriptive analysis, and results are reported as mean and SD.

As in the Australian and UK studies that investigated EMT and paramedic core competencies, a data-reduction approach using factor analysis to summarize the core competencies into factors was adapted for this study. ${ }^{3,13}$ PCA is a multivariate analytical approach used in datasets with multiple dependent variables to create a new set of orthogonal variables - also known as latent variables - that contain the same information as the original set. ${ }^{14}$ The benefits of PCA as a data-reduction method include reduction of the dataset's dimension, generation of fewer variables (or factors) from the original dataset, and facilitation of information summarization and exploration of new ideas by researchers. ${ }^{14}$ In this study, PCA was used to group the 61 items into factors that contained core competencies with similar information. Text analysis was conducted on the answers to the open-ended questions in the third section of the questionnaire to extract key terms and sentences for further analysis. Key terms and sentences with similar meanings or ideas were measured for frequency of response to specific questions to ensure they were representative across the set of respondents.

\section{Results}

Over the 6-week period during which questionnaires were distributed and collected, 169 responses were received from 12 of the 17 participating fire departments, and 93 of these were validated for further analysis. Breaking up the demographic data for valid responses demonstrated that 84 (90.3\%) respondents were EMT instructors and nine $(9.7 \%)$ were medical directors, with $48.4 \%$ based in the fire departments of New Taipei City and Miaoli. By gender, 84 (90.3\%) were male and $9(9.7 \%)$ were female, and the average age was 34.8 years. The average clinical and teaching experience of EMT instructors and medical directors were 6.4 and 5.5 years, respectively.

Table S2 lists the mean core competency item scores at each EMT level. Across the three EMT levels, EMT-Ps recorded the highest, and EMT-1s recorded the lowest, mean scores. The highest average score items for EMT-Ps, EMT-2s, and EMT-1s were "Practice within an approved scope of practice", "Drive ambulance or emergency response vehicle", and "Operate within appropriate ethical and legal boundaries". The lowest average score item across the three EMT levels was "Transfer patient to air ambulance".

Analysis of EMT-1 competence factors started with five factors (Table 1); however, the loadings of 18 items were either similar across factors or the meaning of items did not fit the factors. After removal, the 43 remaining items were analyzed and three factors with eigenvalues $>1$ were identified, accounting for $77.92 \%$ of the total variance (Table 1 ). Items with loadings $>0.40$ with the factor in question were used to characterize factor solutions. Reliability measurements within each EMT-1 competency factor had internal consistency with Cronbach's alpha scores ranging from 0.99 to 0.84 , representing high reliability within factors. ${ }^{13}$ The three factors were descriptively labeled as follows.

Factor 1 was labeled Professionalism and safety behavior and had 24 items loading to this factor, with mean scores ranging from 0.95 to 0.73 (explained variance $58.9 \%$ ). The top item within Factor 1 was "Operate within appropriate ethical and legal boundaries". Factor 2 was labeled Continuing professional development and caring network in community and had 16 items loaded to this factor, with mean scores ranging from 0.90 to 0.62 (explained variance $16.4 \%$ ). The top item within Factor 2 was "Interpret evidence in medical literature and assess relevance to practice". Factor 3 was labeled Communication skills and had two items loaded to this factor, with loadings ranging from 0.69 to 0.63 (explained variance 2.6\%). The top item within Factor 3 was "Effective written and oral communication skills". Although Factor 3 included only two items (theoretically a minimum of three items per factor is required for factor analysis), Cronbach's alpha reliability measurement indicated that the two items had high internal consistency (alpha $=0.84$ ). 
Table I Correlation matrix (principal component analysis with Varimax rotation) of EMT-I $(n=43)$

\begin{tabular}{|c|c|c|c|c|c|c|}
\hline \multirow[t]{2}{*}{ Factors } & \multicolumn{2}{|c|}{ Items } & \multicolumn{3}{|c|}{ Factors loading } & \multirow[t]{2}{*}{ Communalities } \\
\hline & & & $\mathbf{I}$ & 2 & 3 & \\
\hline Factor I: & 50 & Operate within appropriate ethical and legal boundaries & 0.945 & & & 0.90 \\
\hline professionalism & 45 & Caring and empathic & 0.925 & & & 0.87 \\
\hline and safety behavior & 54 & Exhibit physical strength and fitness consistent with the & 0.903 & & & 0.86 \\
\hline Cronbach's & & requirements of professional practice & & & & \\
\hline \multirow{22}{*}{ alpha $=0.99$} & 44 & Nonjudgmental and nondiscriminatory & 0.899 & & & 0.83 \\
\hline & 47 & Understand their role in providing a primary care health service & 0.899 & & & 0.85 \\
\hline & 49 & Accept guidance from colleagues & 0.898 & & & 0.82 \\
\hline & 57 & Practice within an approved scope of practice & 0.886 & & & 0.81 \\
\hline & 46 & Able to see things from the patients' point of view & 0.882 & & & 0.81 \\
\hline & 53 & Manage stress & 0.875 & & & 0.83 \\
\hline & 52 & $\begin{array}{l}\text { Aware of, and regard for, professional issues such as accountability } \\
\text { and confidentiality }\end{array}$ & 0.856 & & & 0.82 \\
\hline & 58 & Develop and maintain personal health and wellbeing strategies & 0.851 & & & 0.76 \\
\hline & 32 & Adhere to a code of ethics & 0.846 & & & 0.74 \\
\hline & 59 & $\begin{array}{l}\text { Respond to changes in the provision of healthcare due to evolving } \\
\text { community expectations }\end{array}$ & 0.839 & & & 0.83 \\
\hline & 48 & Good understanding of their patients' welfare & 0.836 & & & 0.85 \\
\hline & 61 & Embrace social responsibility & 0.834 & & & 0.72 \\
\hline & 60 & $\begin{array}{l}\text { Understand the role of paramedic care within the broader } \\
\text { healthcare system }\end{array}$ & 0.825 & & & 0.80 \\
\hline & 37 & Practice infection control & 0.818 & & & 0.79 \\
\hline & 41 & Conduct ongoing assessments and provide care & 0.806 & & & 0.83 \\
\hline & 35 & $\begin{array}{l}\text { Recognize and react appropriately to persons exhibiting emotional } \\
\text { reactions }\end{array}$ & 0.802 & & & 0.80 \\
\hline & 56 & Trustworthy & 0.801 & & & 0.79 \\
\hline & 42 & Drive ambulance or emergency response vehicle & 0.793 & & & 0.66 \\
\hline & 51 & Ability to work independently as well as a member of a team & 0.748 & 0.437 & & 0.75 \\
\hline & 34 & $\begin{array}{l}\text { Collaborate with law enforcement agencies in the management of } \\
\text { crime scenes }\end{array}$ & 0.746 & & & 0.70 \\
\hline & 55 & Able to provide leadership, mentoring and supervision skills & 0.743 & 0.446 & & 0.76 \\
\hline & 40 & Provide care to meet the needs of unique patient group & 0.727 & 0.503 & & 0.81 \\
\hline $\begin{array}{l}\text { Factor 2: continuing } \\
\text { professional }\end{array}$ & 12 & $\begin{array}{l}\text { Interpret evidence in medical literature and assess relevance to } \\
\text { practice }\end{array}$ & & 0.904 & & 0.86 \\
\hline development and & 11 & Audit, reflect on and review practice & & 0.862 & & 0.76 \\
\hline caring network & 13 & Integrate professional practice into community care & & 0.859 & & 0.77 \\
\hline in community & 18 & Clinical reasoning skills & & 0.856 & & 0.78 \\
\hline Cronbach's & 6 & Capacity to undertake self-directed approaches to learning & & 0.834 & & 0.80 \\
\hline \multirow[t]{11}{*}{ alpha $=0.97$} & 7 & Continue to learn and to help others to learn & & 0.833 & & 0.79 \\
\hline & 9 & Capacity for enquiry and research & & 0.827 & & 0.75 \\
\hline & 15 & Critical thinking & & 0.819 & & 0.73 \\
\hline & 14 & $\begin{array}{l}\text { Contribute to public safety through collaboration with other } \\
\text { emergency response agencies }\end{array}$ & & 0.811 & & 0.75 \\
\hline & 19 & Clinical competence & & 0.811 & & 0.76 \\
\hline & 24 & Apply knowledge of the basic sciences & 0.426 & 0.746 & & 0.75 \\
\hline & 23 & Theoretical knowledge & 0.495 & 0.733 & & 0.79 \\
\hline & 10 & $\begin{array}{l}\text { Ability to learn including the ability to use reflection and learn from } \\
\text { experience }\end{array}$ & & 0.724 & & 0.64 \\
\hline & 16 & $\begin{array}{l}\text { Respectful and consider moral, ethical, social, religious aspects of } \\
\text { healthcare }\end{array}$ & & 0.711 & & 0.66 \\
\hline & 29 & $\begin{array}{l}\text { Use clinical reasoning and problem-solving skills to determine clinical } \\
\text { judgments and appropriate actions }\end{array}$ & 0.511 & 0.679 & & 0.73 \\
\hline & 4 & Commitment to self-development & & 0.622 & 0.554 & 0.71 \\
\hline Factor 3: & 3 & Effective written and oral communication skills & & 0.574 & 0.686 & 0.82 \\
\hline $\begin{array}{l}\text { communication } \\
\text { skills Cronbach's } \\
\text { alpha }=0.84\end{array}$ & 2 & $\begin{array}{l}\text { Capacity to use communication and information technology } \\
\text { effectively and appropriately }\end{array}$ & & 0.505 & 0.632 & 0.70 \\
\hline Eigenvalue & & & 25.353 & 7.051 & $\mathrm{I} .104$ & \\
\hline Explained variance (\%) & & & 58.961 & 16.398 & 2.568 & \\
\hline
\end{tabular}

Note: The items in gray shading belongs to Factor loading.

Abbreviation: EMT, Emergency Medical Technician. 
Factor analysis of EMT-2 competencies began with four factors (Table 2); however, the loadings of 12 items were removed as a result of being similar across factors or because of the meaning of items not fitting the factors. Analysis of the 49 remaining items identified three factors with eigenvalues $>1$, accounting for $81.08 \%$ of the total variance (Table 2). Items with loadings $>0.40$ for the factor in question were used to characterize the factor solutions. Reliability measurements for each factor of EMT-2 competency had good internal consistency, with Cronbach's alpha scores ranging from 0.99 to 0.95 . The three factors were descriptively labeled as follows.

Factor 1 was labeled Professionalism and safety behavior, with a loading of 34 items and mean scores ranging from 0.94 to 0.68 (explained variance $65.01 \%$ ). The top item within the factor was "Operate within appropriate ethical and legal boundaries". Factor 2 was Continuing professional development and collaborative communication skills and nine items were loaded to this factor, with mean scores ranging from 0.81 to 0.62 (explained variance $13.06 \%$ ). The top item within the factor was "Commitment to self-development". Factor 3 was ascribed the label Performing clinical reasoning skills and providing integrated caring network in community, with six items loading to this factor and mean scores ranging from 0.79 to 0.74 (explained variance $3.01 \%$ ). The top item within Factor 3 was "Clinical reasoning skills".

In Table 3, nine factors were initially used to analyze the results of the EMT-P competence factors. Loading revealed that 29 items were either similar across factors or the meaning of items did not fit the factors, which reduced the number of items for analysis to 32. Five factors with eigenvalues $>1$, accounting for $73.56 \%$ of the total variance, were identified (Table 3). Items with loadings $>0.40$ with the factor in question were used to characterize factor solutions. Each factor of EMT-P competency had good internal consistency, with Cronbach's alpha scores ranging from 0.96 to 0.70 . The five factors were descriptively labeled as follows.

Factor 1 was labeled Clinical competency and professionalism, with 12 items loading on this factor and mean scores ranging from 0.79 to 0.56 (explained variance $51.1 \%$ ). The top item within Factor 1 was "Conducts appropriate diagnostic or monitoring procedures, treatment, therapy, or other actions safely". Factor 2 was labeled Patient-centered practice, on to which six items were loaded with mean scores ranging from 0.82 to 0.58 (explained variance $9.9 \%$ ). The top item within Factor 2 was "Caring and empathic". Six items were loaded to Factor 3, Continuing professional development, with mean scores ranging from 0.85 to 0.59 (explained variance $4.7 \%$ ). The top item within Factor 3 was "Willing to undertake ongoing education". Factor 4 was labeled Comprehensive management of self-condition and patient safety. Five items were loaded to this factor, and mean scores ranged from 0.74 to 0.62 (explained variance $4.5 \%$ ); the top item within the factor was "Manage stress". Factor 5 was labeled Clinical reasoning skills, on to which were loaded three items. Mean scores ranged from 0.74 to 0.55 (explained variance $3.4 \%$ ) and the top item was "Interpret evidence in medical literature and assess relevance to practice".

At all EMT levels, "Professionalism" was identified as a core competency factor; however, the items included within the "Professionalism" factor differed between EMT levels. Items relating to professionalism were common to both EMT-1s and EMT-2s and appeared under the same factor label - "Professionalism and safety behavior". Furthermore, competency factors at EMT-1 and EMT-2 levels included "continuing professional development", "communication skills", and "integrated caring network in community". Due to different loadings and distribution, the EMT-1 competency factors were "Continuing professional development and caring network in community" and "Communication skills"; for EMT-2s, the factors were "Continuing professional development and collaboration communication skills" and "Performing clinical reasoning skills and providing integrated caring network in community". Of the five factors attributed to EMT-Ps, two contained similar themes to those at the EMT-1 and EMT-2 levels, such as professionalism and continuing professional development. The factors that only appeared at the EMT-P level were "Patient-centered practice", "Comprehensive management of self-condition and patient safety", and "Clinical reasoning skills".

Section 3 of the questionnaire consisted of multiplechoice questions and related open-ended questions that investigated perspectives of participants with regard to the key factors that may affect current and future EMS training and education in Taiwan. The results from this section indicated that most participants agreed "Attitude from authority agencies", "Licensure system", and "Legislation" were the key factors with regard to the EMS education system and its future development in tertiary education.

The open-ended questions provided opportunities for participants to freely answer questions about the EMS training curriculum and education system in Taiwan. Participants highlighted the following issues as areas for concern: "training hours"; "training curriculum"; "current working environment"; "job opportunity and salary"; "quality control in EMS education"; training and licensure standards'; “consistence training contents and scope of practice"; "learning 
Table 2 Correlation matrix (principal component analysis with Varimax rotation) of EMT-2 ( $n=49)$

\begin{tabular}{|c|c|c|c|c|c|c|}
\hline \multirow[t]{2}{*}{ Factors } & \multicolumn{2}{|c|}{ Items } & \multicolumn{3}{|c|}{ Factors loading } & \multirow[t]{2}{*}{ Communalities } \\
\hline & & & $\mathbf{I}$ & 2 & 3 & \\
\hline Factor I: professionalism & 50 & Operate within appropriate ethical and legal boundaries & 0.944 & & & 0.91 \\
\hline and safety behavior & 49 & Accept guidance from colleagues & 0.936 & & & 0.91 \\
\hline \multirow[t]{34}{*}{ Cronbach's alpha $=0.99$} & 52 & $\begin{array}{l}\text { Aware of and regard for, professional issues such as } \\
\text { accountability and confidentiality }\end{array}$ & 0.936 & & & 0.92 \\
\hline & 45 & Caring and empathic & 0.933 & & & 0.90 \\
\hline & 57 & Practice within an approved scope of practice & 0.932 & & & 0.89 \\
\hline & 56 & Trustworthy & 0.932 & & & 0.93 \\
\hline & 47 & $\begin{array}{l}\text { Understand their role in providing a primary care health } \\
\text { service }\end{array}$ & 0.927 & & & 0.90 \\
\hline & 46 & Able to see things from the patients' point of view & 0.924 & & & 0.90 \\
\hline & 54 & $\begin{array}{l}\text { Exhibit physical strength and fitness consistent with the } \\
\text { requirements of professional practice }\end{array}$ & 0.920 & & & 0.89 \\
\hline & 42 & Drive ambulance or emergency response vehicle & 0.912 & & & 0.84 \\
\hline & 41 & Conduct ongoing assessments and provide care & 0.907 & & & 0.92 \\
\hline & 44 & Nonjudgmental and nondiscriminatory & 0.904 & & & 0.84 \\
\hline & 51 & Ability to work independently as well as a member of a team & 0.900 & & & 0.89 \\
\hline & 48 & Good understanding of their patients' welfare & 0.894 & & & 0.88 \\
\hline & 53 & Manage stress & 0.893 & & & 0.87 \\
\hline & 58 & Develop and maintain personal health and wellbeing strategies & 0.885 & & & 0.82 \\
\hline & 35 & $\begin{array}{l}\text { Recognize and react appropriately to persons exhibiting } \\
\text { emotional reactions }\end{array}$ & 0.882 & & & 0.87 \\
\hline & 38 & Conduct triage in a multiple-patient incident & 0.881 & & & 0.87 \\
\hline & 60 & $\begin{array}{l}\text { Understand the role of paramedic care within the broader } \\
\text { healthcare system }\end{array}$ & 0.880 & & & 0.84 \\
\hline & 55 & Able to provide leadership, mentoring and supervision skills & 0.879 & & & 0.86 \\
\hline & 37 & Practice infection control & 0.879 & & & 0.86 \\
\hline & 59 & $\begin{array}{l}\text { Respond to changes in the provision of healthcare due to } \\
\text { evolving community expectations }\end{array}$ & 0.876 & & & 0.85 \\
\hline & 61 & Embrace social responsibility & 0.876 & & & 0.80 \\
\hline & 32 & Adhere to a code of ethics & 0.875 & & & 0.80 \\
\hline & 31 & $\begin{array}{l}\text { Apply infection control procedures which recognize risks to } \\
\text { patients and those treating them }\end{array}$ & 0.867 & & & 0.83 \\
\hline & 30 & $\begin{array}{l}\text { Act in accordance with applicable health and safety legislation, } \\
\text { and any relevant safety policies and procedures }\end{array}$ & 0.853 & & & 0.83 \\
\hline & 39 & $\begin{array}{l}\text { Utilize differential diagnosis skills, decision-making skills and } \\
\text { psychomotor skills in providing care to patients }\end{array}$ & 0.848 & & & 0.89 \\
\hline & 40 & Provide care to meet the needs of unique patient group & 0.834 & & & 0.86 \\
\hline & 33 & $\begin{array}{l}\text { Demonstrates the requisite knowledge and skills to participate } \\
\text { in mass casualty or major incident }\end{array}$ & 0.833 & & & 0.84 \\
\hline & 34 & $\begin{array}{l}\text { Collaborate with law enforcement agencies in the } \\
\text { management of crime scenes }\end{array}$ & 0.831 & & & 0.79 \\
\hline & 36 & Conduct procedures and operations consistent with & 0.811 & & & 0.85 \\
\hline & & Workplace Hazardous Materials Information System (WHMIS) & & & & \\
\hline & & and hazardous materials management requirement & & & & \\
\hline & 27 & Maintain records appropriately & 0.746 & & & 0.76 \\
\hline & 29 & $\begin{array}{l}\text { Use clinical reasoning and problem-solving skills to determine } \\
\text { clinical judgments and appropriate actions }\end{array}$ & 0.691 & & 0.437 & 0.73 \\
\hline & 43 & Transfer patient to air ambulance & 0.675 & & & 0.55 \\
\hline Factor 2: continuing & 4 & Commitment to self-development & & 0.813 & & 0.74 \\
\hline professional & 3 & Effective written and oral communication skills & & 0.791 & & 0.67 \\
\hline development and & I & Able to work in interdisciplinary teams & & 0.766 & & 0.67 \\
\hline collaboration & 2 & Capacity to use communication and information technology & & 0.758 & & 0.67 \\
\hline communication skills & & effectively and appropriately & & & & \\
\hline \multirow[t]{3}{*}{ Cronbach's alpha $=0.93$} & 6 & Capacity to undertake self-directed approaches to learning & & 0.714 & 0.475 & 0.77 \\
\hline & 7 & Continue to learn and to help others to learn & & 0.694 & 0.478 & 0.74 \\
\hline & 5 & Assess scene for safety & & 0.685 & & 0.53 \\
\hline
\end{tabular}


Table 2 (Continued)

\begin{tabular}{|c|c|c|c|c|c|c|}
\hline \multirow[t]{2}{*}{ Factors } & \multicolumn{2}{|c|}{ Items } & \multicolumn{3}{|c|}{ Factors loading } & \multirow[t]{2}{*}{ Communalities } \\
\hline & & & $\mathbf{I}$ & 2 & 3 & \\
\hline & 9 & Capacity for enquiry and research & & 0.666 & 0.474 & 0.69 \\
\hline & 10 & $\begin{array}{l}\text { Ability to learn including the ability to use reflection and learn } \\
\text { from experience }\end{array}$ & & 0.620 & 0.433 & 0.64 \\
\hline Factor 3: performing & 18 & Clinical reasoning skills & & & 0.794 & 0.84 \\
\hline clinical reasoning skills & 19 & Clinical competence & & & 0.777 & 0.82 \\
\hline $\begin{array}{l}\text { and providing integrated } \\
\text { caring network in }\end{array}$ & 12 & $\begin{array}{l}\text { Interpret evidence in medical literature and assess relevance } \\
\text { to practice }\end{array}$ & & 0.428 & 0.763 & 0.83 \\
\hline community Cronbach's & 13 & Integrate professional practice into community care & & & 0.739 & 0.69 \\
\hline \multirow[t]{2}{*}{ alpha $=0.95$} & 15 & Critical thinking & & & 0.738 & 0.74 \\
\hline & 14 & $\begin{array}{l}\text { Contribute to public safety through collaboration with other } \\
\text { emergency response agencies }\end{array}$ & & & 0.737 & 0.80 \\
\hline Eigenvalue & & & 31.858 & 6.398 & 1.474 & \\
\hline Explained variance (\%) & & & 65.015 & 13.058 & 3.008 & \\
\hline
\end{tabular}

Note: The items in gray shading belongs to Factor loading.

Abbreviation: EMT, Emergency Medical Technician.

accessibility (such as e-learning portal)"; "qualification of training organization and instructors"; "independent EMS department (not part of the fire department)"; "local government's budget in EMS development"; and "international EMS networking". Educators highlighted the importance of establishing EMS academies or emergency health departments in colleges and universities to improve the overall quality of EMS education. Furthermore, it would benefit the performance of EMTs by providing impetus to EMS-based research that could be used as an evidence base to improve the Taiwanese EMS system.

\section{Discussion}

The results revealed consensus among EMT-1s and EMT-2s that "Professionalism and safety behavior", "Continuing professional development", "Communication skills", and "Integrated caring network in community" represent core competencies for the EMT role. This is a key finding with implications for future EMT curricula design in Taiwan. To meet the core competencies identified at the EMT-1 level, students would be required to complete 40 hours of training under the current training curriculum standardized module. Subjects covered include basic concepts, basic life support, patient assessment, basic skills, scenarios, and megacodes, many of which are also included in the current EMT-2 training curriculum. The findings suggest that EMT-1 and EMT-2 curricula require modification, and it is recommended that EMT-1 and EMT-2 are combined as a single level.

Medical directors and EMT-Ps, furthermore, identified professionalism and continuing professional development as integral to the EMT role. The current training curriculum standards for EMT-Ps include nine modules, with a requirement for students to complete 1,280 hours of training; however, course content is predominantly skill-focused. ${ }^{2}$ Comparison of the findings at the EMT-P level with current training standards revealed that the five competency factors identified by EMT-Ps do not feature in the current curriculum. The emphasis on skills-based performance within the curriculum suggests that the EMT-Ps' requirements for training in core competencies are not currently being met. In addition to professionalism and continuing professional development, the findings revealed that training of EMT-Ps in clinical skills should be augmented by education in other essential areas, including patient-centered care, clinical reasoning skills, and comprehensive management of self and patients.

Current EMS training standards in Taiwan are adapted from the US system, which has four levels of EMT status in contrast to the three levels in Taiwan. ${ }^{1,15}$ Under current Taiwanese EMT classification standards, EMT-1, EMT-2, and EMT-P are similar to EMR, EMT, and Paramedics in the USA. ${ }^{2,15}$ EMT-1 and EMT-2 competency factors in this study can be identified at a level between EMT and AEMT in the USA, whereas the EMT-P level in Taiwan and Paramedic level in the USA have similar competency items. ${ }^{2,15}$

A comparison of the findings from this study with international EMT/Paramedic competencies highlights the absence - at EMT-1 and EMT-2 levels in Taiwan - of the following core competencies: "Clinical decision making", "Identifying and assessing social care", "Academic skills", and "Interprofessional skills". At the EMT-P level, the competency factor covers more international competencies than at the other two levels; however, "Academic skills" and "Interprofessional skills" are not identified. 
Table 3 Correlation matrix (principal component analysis with Varimax rotation) of EMT-P $(n=32)$

\begin{tabular}{|c|c|c|c|c|c|c|c|c|}
\hline \multirow[t]{2}{*}{ Factors } & \multicolumn{2}{|c|}{ Items } & \multicolumn{5}{|c|}{ Factors loading } & \multirow[t]{2}{*}{ Communalities } \\
\hline & & & $\mathbf{I}$ & 2 & 3 & 4 & 5 & \\
\hline $\begin{array}{l}\text { Factor I: clinical } \\
\text { competency and } \\
\text { professionalism }\end{array}$ & 26 & $\begin{array}{l}\text { Conduct appropriate diagnostic or monitoring } \\
\text { procedures, treatment, therapy or other actions } \\
\text { safely }\end{array}$ & 0.788 & & & & & 0.84 \\
\hline Cronbach's & 56 & Trustworthy & 0.735 & & & & & 0.76 \\
\hline \multirow[t]{10}{*}{ alpha $=0.96$} & 28 & $\begin{array}{l}\text { Specialist knowledge (eg, practitioner or extended } \\
\text { scope roles) }\end{array}$ & 0.724 & & & & & 0.79 \\
\hline & 57 & Practice within an approved scope of practice & 0.723 & & & & & 0.77 \\
\hline & 55 & $\begin{array}{l}\text { Able to provide leadership, mentoring and } \\
\text { supervision skills }\end{array}$ & 0.706 & & & & & 0.75 \\
\hline & 39 & $\begin{array}{l}\text { Utilize differential diagnosis skills, decision-making } \\
\text { skills and psychomotor skills in providing care to } \\
\text { patients }\end{array}$ & 0.674 & & & & & 0.78 \\
\hline & 29 & $\begin{array}{l}\text { Use clinical reasoning and problem-solving skills } \\
\text { to determine clinical judgments and appropriate } \\
\text { actions }\end{array}$ & 0.652 & & & & 0.484 & 0.80 \\
\hline & 41 & Conduct ongoing assessments and provide care & 0.643 & & 0.435 & & & 0.80 \\
\hline & 25 & $\begin{array}{l}\text { Formulate specific and appropriate patient care and } \\
\text { treatment actions }\end{array}$ & 0.623 & & & & 0.527 & 0.80 \\
\hline & 27 & Maintain records appropriately & 0.620 & & & & & 0.71 \\
\hline & 37 & Practice infection control & 0.578 & & & & & 0.57 \\
\hline & 19 & Clinical competence & 0.558 & & & & 0.510 & 0.78 \\
\hline Factor 2: patient- & 45 & Caring and empathic & & 0.821 & & & & 0.83 \\
\hline centered practice & 44 & Nonjudgmental and nondiscriminatory & & 0.807 & & & & 0.67 \\
\hline \multirow[t]{4}{*}{$\begin{array}{l}\text { Cronbach's } \\
\text { alpha }=0.91\end{array}$} & 50 & $\begin{array}{l}\text { Operate within appropriate ethical and legal } \\
\text { boundaries }\end{array}$ & & 0.785 & & & & 0.69 \\
\hline & 49 & Accept guidance from colleagues & & 0.782 & & & & 0.76 \\
\hline & 46 & Able to see things from the patients' point of view & & 0.723 & & & & 0.73 \\
\hline & 51 & $\begin{array}{l}\text { Ability to work independently as well as a member } \\
\text { of a team }\end{array}$ & 0.502 & 0.578 & & & & 0.66 \\
\hline Factor 3: continuing & 8 & Willing to undertake ongoing education & & & 0.845 & & & 0.82 \\
\hline professional & 9 & Capacity for enquiry and research & & & 0.721 & & & 0.77 \\
\hline $\begin{array}{l}\text { development } \\
\text { Cronbach's }\end{array}$ & 6 & $\begin{array}{l}\text { Capacity to undertake self-directed approaches to } \\
\text { learning }\end{array}$ & & & 0.700 & & 0.445 & 0.78 \\
\hline \multirow[t]{3}{*}{ alpha $=0.90$} & 1 & Able to work in interdisciplinary teams & & & 0.687 & & & 0.59 \\
\hline & 11 & Audit, reflect on and review practice & & & 0.670 & & & 0.71 \\
\hline & 7 & Continue to learn and to help others to learn & & & 0.589 & & 0.475 & 0.73 \\
\hline Factor 4: & 53 & Manage stress & & 0.450 & & 0.737 & & 0.78 \\
\hline comprehensive & 36 & Conduct procedures and operations consistent with & & & & 0.662 & & 0.74 \\
\hline $\begin{array}{l}\text { management of self- } \\
\text { condition and patient } \\
\text { safety Cronbach's }\end{array}$ & & $\begin{array}{l}\text { Workplace Hazardous Materials Information System } \\
\text { (WHMIS) and hazardous materials management } \\
\text { requirement }\end{array}$ & & & & & & \\
\hline \multirow[t]{3}{*}{ alpha $=0.86$} & 54 & $\begin{array}{l}\text { Exhibit physical strength and fitness consistent with } \\
\text { the requirements of professional practice }\end{array}$ & & 0.551 & & 0.661 & & 0.82 \\
\hline & 43 & Transfer patient to air ambulance & & & & 0.659 & & 0.63 \\
\hline & 34 & $\begin{array}{l}\text { Collaborate with law enforcement agencies in the } \\
\text { management of crime scenes }\end{array}$ & 0.461 & & & 0.619 & & 0.70 \\
\hline $\begin{array}{l}\text { Factor } 5 \text { : clinical } \\
\text { reasoning skills }\end{array}$ & 12 & $\begin{array}{l}\text { Interpret evidence in medical literature and assess } \\
\text { relevance to practice }\end{array}$ & & & & & 0.736 & 0.75 \\
\hline Cronbach's & 15 & Critical thinking & & & & & 0.644 & 0.49 \\
\hline alpha $=0.70$ & 18 & Clinical reasoning skills & 0.532 & & & & 0.545 & 0.74 \\
\hline Eigenvalue & & & 16.364 & 3.155 & 1.508 & 1.435 & 1.078 & \\
\hline Explained variance $(\%)$ & & & 51.139 & 9.859 & 4.712 & 4.484 & 3.367 & \\
\hline
\end{tabular}

Note: The items in gray shading belongs to Factor loading.

Abbreviation: EMT, Emergency Medical Technician. 
In countries with vocational EMS training systems, including Taiwan, there is no training in academic skills at the EMT/Paramedic level, and the development of academic skills is restricted to the university-based educational environment. ${ }^{16}$ The literature on vocational training suggests that university students have less exposure to clinical practice in the field than those students training in industrial paramedicine. Evidence, however, suggests that the comprehensive medical and health science knowledge learned in universities assists in maintaining a balance between theory and practical application, and better meets the requirements of becoming a healthcare practitioner. ${ }^{16,17}$ The results from the current study reveal a failure of the current EMS training system in Taiwan to recognize academic skills as a core competency for EMTs, and highlights the opportunity for future improvements in establishing a university-based education environment for EMTs.

Interprofessional work is a common feature within all healthcare environments, whereby professionals from all healthcare disciplines work together in providing care for a patient. ${ }^{18}$ Previous research has stressed the importance and necessity of incorporating interprofessional education (IPE) in EMT/paramedic curriculum. ${ }^{18,19}$ Williams et al emphasize that the timing when IPE is introduced is essential and that it must be viewed as a professional development process for paramedics. The findings from this study identified no interprofessional competencies at any level of EMT. As the demand for EMS services increases in Taiwan, IPE will be a key professional competence for EMTs that will contribute to more effective practice and improve the efficiency of the healthcare system.

The results demonstrated no significant differences in competency item scores between all levels of EMTs based on the participants' qualifications and experience. As key stakeholders in promoting the development of the EMS education system in Taiwan, the consistency of results and consensus among EMS educators with regard to core competencies highlights the significant role of medical directors and EMT-Ps in providing future opportunities to innovate and promote EMS education in Taiwan.

Three main issues emerged from the responses to the open-ended questions that potentially impact the future development and professionalization of the EMS education system in Taiwan: the attitude of the governing EMS agencies; legislation; and the licensure system. It is important to note that the survey participants, including EMT instructors, are government employees who are required to carry out managerial commands and policies. The attitude of governing
EMS agencies was, therefore, identified as the most important issue in the future development of the EMS education system. The agencies responsible for managing EMS education in Taiwan - and with the authority to decide policy and legislation - are the Health Department and National Fire Agency. The support of these two agencies will be key to directing future practice and scope in the prehospital setting; however, the traditionally conservative attitude of the Taiwanese authorities toward EMS education represents a barrier to future development. The lawmaking process takes times, and the fact that most EMT-Ps are government employees means that they are not easily placed to promote EMS education from within a hierarchical and medically dominated system. The same issues relate to modifying the legislation; enacting change to the licensure system would require the support of the relevant authorities. Participants indicated that developing a national registration system and establishing a tertiary-based EMS education system in the future is the preferred approach for improving the overall quality of EMS education in Taiwan and developing the body of knowledge within the EMS discipline. In addition, introducing EMS licensure and a degree-based EMS education system would promote further work-related opportunities for EMTs, thereby enhancing the standing of the profession within the Taiwanese healthcare sector.

\section{Limitations}

The low response rate is an acknowledged limitation. EMS divisions in the local fire departments forwarded questionnaires to participants online but did not issue follow-up communications to encourage recipients to reply. Moreover, the high number of questions in the questionnaire may have affected the response rate as it is rare in the context of healthcare research in Taiwan for questionnaires to include 80 questions. The 70 incomplete (invalid) replies were the result of settings in the Qualtrics Platform where participants had the option of reserving their responses prior to submission. The default setting for reservation was 7 days, with incomplete responses automatically submitted to the database after Day 7, which resulted in a high number of invalid responses.

\section{Future research}

The attitude of authorities is the key factor affecting the future development of the EMS education system in Taiwan and it is, therefore, essential to secure the agreement of relevant authorities and stakeholders to conduct further research in this area. The findings will provide an evidencebase and blueprint for expanding EMS curricula content and 
reallocating course and total training hours to provide more accurate competency-based training at all levels of EMT.

\section{Conclusion}

Core competencies are regarded as the foundation for establishing EMT and paramedic curricula and the delivery of high-quality prehospital care. The findings from this study indicated that the core competencies at the EMT-1 and EMT-2 levels were very similar, and it is recommended that curricula are redesigned and the roles of EMT-1s and EMT-2s are reconsidered. At the EMT-P level, the results demonstrate the important of incorporating competency standards in the current skills-based curriculum to ensure that EMTs operating at the highest levels practice competently. Furthermore, the competency gap between all levels of EMT and internationally recognized core competencies must be addressed. Identification of core competencies and key factors at each level of EMT is the first step in producing an evidence base to inform the future development of the EMS education system in Taiwan.

\section{Disclosure}

The authors report no conflicts of interest in this work.

\section{References}

1. National Fire Agency. Emergency Medical Technician 1 Training Material. 1st ed. New Taipei City: National Fire Agency; 2017.

2. Emergency Medical Technicians Administration Regulation. Taiwan; 1996. Available from: http://law.moj.gov.tw/LawClass/LawAll. aspx?PCode=L0020141. Accessed March 1, 2018

3. Williams B, Onsman A, Brown T. Australian paramedic graduate attributes: a pilot study using exploratory factor analysis. Emerg Med J. 2010;27(10):794-799.

4. Kilner T. Desirable attributes of the ambulance technician, paramedic, and clinical supervisor: findings from a Delphi study. Emerg Med J. 2004;21(3):374-378.

5. Health Professional Council of South Africa. Professional Board for Emergency Care: Emergency Care Assistant. Pretoria, South Africa: Health Professional Council of South Africa; 2016.
6. College of Paramedics. Paramedic Curriculum Guidance. 3rd ed. Bridgwater, UK: College of Paramedics; 2014;7-10.

7. Prehospital Emergency Care Council. STN016 - Advanced Paramedic Education and Training Standard-V1. 2014;3:18-30. Available from: URLhttp://www.phecit.ie/Images/PHECC/Career\%20and $\% 20$ Education/Education\%20Standards/STN016\%20Advanced $\% 20$ Paramedic\%20Education\%20and\%20Training\%20Standard-V1.pdf. Accessed March 1, 2018

8. National Highway Traffic Safety Administration. National EMS Scope of Practice Model. 2007:21-31. Available from: https://www.ems.gov/ pdf/education/EMS-Education-for-the-Future-A-Systems-Approach/ National_EMS_Scope_Practice_Model.pdf. Accessed March 1, 2018

9. Paramedic Association of Canada. National Occupational Competency Profile for Paramedic Association of Canada. October 2011. Available from: http://www.paramedic.ca/uploaded/web/documents/201110-31-Approved-NOCP-English-Master.pdf. Accessed March 1, 2018.

10. Council of Ambulance Authorities Inc. Professional Competency Standards Paramedics. 2010;1-18. Available from: www.caa.net.au/images/ documents/accreditation_resources/Paramedic_Professional_Competency_Standards_V2.2_February_2013_PEPAS.pdf. Accessed March 1,2018

11. Melorose J, Perroy R, Careas S. Core Competencies Guideline Sheet of Scotland Ambulance. Statew Agric L Use Baseline. 2015;1. Available from: http://www.scottishambulance.com/UserFiles/file/TechApplicationForm/2.\%20CORE\%20COMPETENCY\%20GUIDANCE\%20 -\%20TECHNICIAN.pdf. Accessed March 1, 2018

12. Chang YT, Tsai KC, Williams B. What are the educational and curriculum needs for emergency medical technicians in Taiwan? A scoping review. Adv Med Educ Pract. 2017;8:649-667.

13. Kilner T. Educating the ambulance technician, paramedic, and clinical supervisor: using factor analysis to inform the curriculum. Emerg Med J. 2004;21(3):379-385.

14. Sharma S. Applied Multivariate Techniques. Chichester: John Wiley; 1996:1.

15. National Highway Traffic Safety Administration. National EMS Education Standards. NHTSA; 2009. Available from: https://www.ems.gov/ pdf/education/EMS-Education-for-the-Future-A-Systems-Approach/ National_EMS_Education_Standards.pdf

16. Willis E, Williams B, Brightwell R, O'Meara P, Pointon T. Road-ready paramedics and the supporting sciences curriculum. Focus Health Prof Educ J. 2010;11(2):1-13.

17. O'Meara P, Ruest M, Stirling C. Community paramedicine: higher education as an enabling factor. Australasian J Paramed. 2014;11(2).

18. Williams B, Boyle M, Brightwell R, et al. A cross-sectional study of paramedics' readiness for interprofessional learning and cooperation: results from five universities. Nurse Educ Today. 2013;33(11):1369-1375.

19. Hallikainen J, Väisänen O, Rosenberg PH, Silfvast T, Niemi-Murola L. Interprofessional education of medical students and paramedics in emergency medicine. Acta Anaesthesiol Scand. 2007;51(3):372-377. 


\section{Supplementary materials}

Table SI Overview of global EMT/paramedic competencies and standards I 2

\begin{tabular}{|c|c|c|c|c|c|c|c|}
\hline Items/countries & Taiwan & Australia & USA & UK & Ireland & Canada & South Africa \\
\hline Education/training system & Vocational & University & Both & Both & Both & Vocational & Both \\
\hline Professionalism & $\mathrm{x}$ & $x$ & $x$ & $x$ & $x$ & $x$ & $x$ \\
\hline Clinical decision-making & & $x$ & $x$ & $x$ & $x$ & $x$ & $x$ \\
\hline Ethics and law & $x$ & $x$ & $x$ & $x$ & $\mathrm{x}$ & $x$ & $x$ \\
\hline Communication & $x$ & $x$ & $x$ & $x$ & $x$ & $x$ & $x$ \\
\hline Demonstration of knowledge & $x$ & $x$ & $x$ & $x$ & $x$ & $x$ & $x$ \\
\hline Occupational safety & & $x$ & $x$ & $x$ & $x$ & $x$ & $x$ \\
\hline Identifying and assessing social care & & $x$ & $x$ & $x$ & $x$ & $x$ & $x$ \\
\hline Identifying and assessing mental care & $x$ & $x$ & $x$ & $x$ & $x$ & $x$ & $x$ \\
\hline Identifying and assessing healthcare & $x$ & $x$ & $x$ & $x$ & $x$ & $x$ & $x$ \\
\hline Formulating and delivering clinical practice & $x$ & $x$ & $x$ & $x$ & $\mathrm{x}$ & $\mathrm{X}$ & $\mathrm{x}$ \\
\hline Clinical skills & $x$ & $\mathrm{x}$ & $\mathrm{x}$ & $x$ & $\mathrm{x}$ & $x$ & $\mathrm{x}$ \\
\hline Criticality assessment & $x$ & $x$ & $x$ & $x$ & $x$ & $x$ & $x$ \\
\hline Academic skills & & $x$ & & $x$ & & & $x$ \\
\hline Interprofessional skills & & $x$ & & & & & $x$ \\
\hline
\end{tabular}

Note: $X$ indicates that the general competency item is included in the competencies and standards document.

Abbreviation: EMT, Emergency Medical Technician.

Table S2 Distribution of scores for the 61 core competency items at all levels of EMT

\begin{tabular}{|c|c|c|c|c|c|c|c|}
\hline \multicolumn{2}{|c|}{ Core competencies } & \multicolumn{2}{|c|}{ EMT-P } & \multicolumn{2}{|l|}{ EMT-2 } & \multicolumn{2}{|l|}{ EMT-I } \\
\hline & & \multirow{2}{*}{$\begin{array}{l}\text { Mean } \\
8.29\end{array}$} & \multirow{2}{*}{$\begin{array}{l}\text { SD } \\
1.39\end{array}$} & \multirow{2}{*}{$\begin{array}{l}\text { Mean } \\
6.41\end{array}$} & \multirow{2}{*}{$\frac{\text { SD }}{1.88}$} & \multirow{2}{*}{$\begin{array}{l}\text { Mean } \\
4.37\end{array}$} & \multirow{2}{*}{$\frac{\text { SD }}{2.62}$} \\
\hline I & Able to work in interdisciplinary teams & & & & & & \\
\hline 2 & $\begin{array}{l}\text { Capacity to use communication and information technology effectively and } \\
\text { appropriately }\end{array}$ & 8.35 & 1.44 & 6.69 & 2.06 & 5.17 & 2.60 \\
\hline 3 & Effective written and oral communication skills & 8.04 & 1.38 & 6.25 & 1.92 & 4.60 & 2.47 \\
\hline 4 & Commitment to self-development & 8.30 & 1.44 & 6.18 & 1.93 & 4.88 & 2.54 \\
\hline 5 & Assess scene for safety & 8.90 & 1.21 & 7.87 & 1.62 & 6.42 & 2.49 \\
\hline 6 & Capacity to undertake self-directed approaches to learning & 8.59 & 1.17 & 6.15 & 1.94 & 4.75 & 2.47 \\
\hline 7 & Continue to learn and to help others to learn & 8.62 & 1.14 & 6.34 & 2.00 & 4.67 & 2.59 \\
\hline 8 & Willing to undertake ongoing education & 8.86 & 1.31 & 7.10 & 2.28 & 6.22 & 2.76 \\
\hline 9 & Capacity for enquiry and research & 8.49 & 1.31 & 5.81 & 2.28 & 4.53 & 2.66 \\
\hline 10 & Ability to learn including the ability to use reflection and learn from experience & 8.67 & 1.18 & 6.74 & 2.11 & 5.62 & 2.73 \\
\hline II & Audit, reflect on and review practice & 8.82 & 1.03 & 6.24 & 2.12 & 4.81 & 2.67 \\
\hline 12 & Interpret evidence in medical literature and assess relevance to practice & 7.54 & 1.98 & 4.86 & 2.47 & 3.75 & 2.78 \\
\hline 13 & Integrate professional practice into community care & 7.00 & 2.30 & 4.87 & 2.61 & 3.99 & 2.75 \\
\hline 14 & $\begin{array}{l}\text { Contribute to public safety through collaboration with other emergency response } \\
\text { agencies }\end{array}$ & 7.69 & 1.78 & 5.83 & 2.39 & 4.70 & 2.85 \\
\hline 15 & Critical thinking & 7.77 & 1.69 & 5.57 & 2.27 & 4.17 & 2.71 \\
\hline 16 & Be respectful and consider moral, ethical, social, religious aspects of healthcare & 8.05 & 1.63 & 6.77 & 2.35 & 6.06 & 2.82 \\
\hline 17 & Culturally sensitive and have an inclusive approach to differences & 8.42 & 1.51 & 7.58 & 2.25 & 7.24 & 2.70 \\
\hline 18 & Clinical reasoning skills & 8.19 & 1.46 & 5.60 & 1.99 & 3.77 & 2.40 \\
\hline 19 & Clinical competence & 8.07 & 1.40 & 5.61 & 2.06 & 4.13 & 2.44 \\
\hline 20 & Literate and numerate & 7.57 & 1.77 & 6.11 & 2.00 & 5.25 & 2.47 \\
\hline 21 & Good listener & 7.94 & 1.96 & 6.93 & 2.08 & 6.42 & 2.62 \\
\hline 22 & Follow evidence-based practice & 8.40 & 1.49 & 6.93 & 2.16 & 6.36 & 2.64 \\
\hline 23 & Theoretical knowledge & 8.40 & 1.30 & 6.06 & 2.12 & 4.64 & 2.64 \\
\hline 24 & Apply knowledge of the basic sciences & 7.64 & 1.82 & 5.95 & 2.21 & 4.75 & 2.63 \\
\hline 25 & Formulate specific and appropriate patient care and treatment actions & 8.40 & 1.27 & 6.58 & 2.01 & 5.36 & 2.73 \\
\hline 26 & $\begin{array}{l}\text { Conduct appropriate diagnostic or monitoring procedures, treatment, therapy or } \\
\text { other actions safely }\end{array}$ & 8.49 & 1.26 & 6.44 & 1.88 & 5.15 & 2.64 \\
\hline 27 & Maintain records appropriately & 8.43 & 1.50 & 7.14 & 2.19 & 6.09 & 2.90 \\
\hline 28 & Specialist knowledge (eg, practitioner or extended scope roles) & 8.33 & 1.29 & 6.04 & 1.90 & 4.62 & 2.52 \\
\hline 29 & $\begin{array}{l}\text { Use clinical reasoning and problem-solving skills to determine clinical judgments and } \\
\text { appropriate actions }\end{array}$ & 8.31 & 1.37 & 5.88 & 1.99 & 4.46 & 2.61 \\
\hline
\end{tabular}


Table S2 (Continued)

\begin{tabular}{|c|c|c|c|c|c|c|c|}
\hline \multicolumn{2}{|c|}{ Core competencies } & \multicolumn{2}{|c|}{ EMT-P } & \multicolumn{2}{|l|}{ EMT-2 } & \multicolumn{2}{|l|}{ EMT-I } \\
\hline 30 & $\begin{array}{l}\text { Act in accordance with applicable health and safety legislation, and any relevant safety } \\
\text { policies and procedures }\end{array}$ & $\begin{array}{l}\text { Mean } \\
8.38\end{array}$ & $\frac{\text { SD }}{1.32}$ & $\begin{array}{l}\text { Mean } \\
6.84\end{array}$ & $\frac{\text { SD }}{2.12}$ & $\begin{array}{l}\text { Mean } \\
5.95\end{array}$ & $\frac{\text { SD }}{2.73}$ \\
\hline 31 & $\begin{array}{l}\text { Apply infection control procedures which recognize risks to patients and those } \\
\text { treating them }\end{array}$ & 8.43 & 1.35 & 6.82 & 2.08 & 5.95 & 2.60 \\
\hline 32 & Adhere to a code of ethics & 8.75 & 1.23 & 7.95 & 1.86 & 7.64 & 2.29 \\
\hline 33 & $\begin{array}{l}\text { Demonstrate the requisite knowledge and skills to participate in mass casualty or } \\
\text { major incident }\end{array}$ & 8.73 & 1.17 & 6.32 & 2.10 & 4.88 & 2.68 \\
\hline 34 & Collaborate with law enforcement agencies in the management of crime scenes & 7.93 & 1.85 & 7.01 & 2.31 & 6.17 & 2.83 \\
\hline 35 & Recognize and react appropriately to persons exhibiting emotional reactions & 8.29 & 1.26 & 6.97 & 1.86 & 6.01 & 2.47 \\
\hline 36 & $\begin{array}{l}\text { Conduct procedures and operations consistent with Workplace Hazardous Materials } \\
\text { Information System (WHMIS) and hazardous materials management requirement }\end{array}$ & 7.78 & 1.80 & 6.14 & 2.15 & 4.67 & 2.73 \\
\hline 37 & Practice infection control & 8.55 & 1.20 & 7.05 & 2.13 & 5.96 & 2.72 \\
\hline 38 & Conduct triage in a multiple-patient incident & 8.93 & 1.19 & 6.95 & 1.89 & 4.89 & 2.76 \\
\hline 39 & $\begin{array}{l}\text { Utilize differential diagnosis skills, decision-making skills and psychomotor skills in } \\
\text { providing care to patients }\end{array}$ & 8.54 & 1.24 & 6.25 & 1.96 & 4.46 & 2.48 \\
\hline 40 & Provide care to meet the needs of unique patient group & 7.83 & 1.73 & 5.88 & 2.15 & 4.77 & 2.68 \\
\hline 41 & Conduct ongoing assessments and provide care & 8.75 & 1.26 & 7.08 & 1.95 & 5.81 & 2.74 \\
\hline 42 & Drive ambulance or emergency response vehicle & 9.07 & 1.11 & 8.61 & 1.58 & 7.41 & 2.93 \\
\hline 43 & Transfer patient to air ambulance & 6.87 & 2.50 & 4.44 & 2.38 & 2.89 & 2.08 \\
\hline 44 & Nonjudgmental and nondiscriminatory & 7.97 & 1.88 & 7.61 & 2.08 & 7.41 & 2.27 \\
\hline 45 & Caring and empathic & 8.45 & 1.54 & 7.95 & 1.92 & 7.72 & 2.20 \\
\hline 46 & Able to see things from the patients' point of view & 8.32 & 1.62 & 7.41 & 1.96 & 7.01 & 2.20 \\
\hline 47 & Understand their role in providing a primary care health service & 8.61 & 1.34 & 7.39 & 2.00 & 6.69 & 2.45 \\
\hline 48 & Good understanding of their patients' welfare & 7.92 & 1.74 & 6.60 & 2.06 & 5.76 & 2.58 \\
\hline 49 & Accept guidance from colleagues & 8.39 & 1.65 & 7.69 & 1.82 & 7.69 & 2.25 \\
\hline 50 & Operate within appropriate ethical and legal boundaries & 8.61 & 1.51 & 8.01 & 1.91 & 7.84 & 2.19 \\
\hline 51 & Ability to work independently as well as a member of a team & 8.89 & 1.46 & 6.99 & 1.99 & 5.03 & 2.66 \\
\hline 52 & Aware of, and regard for, professional issues such as accountability and confidentiality & 8.81 & 1.35 & 7.49 & 1.86 & 6.36 & 2.54 \\
\hline 53 & Manage stress & 7.61 & 1.90 & 6.67 & 2.00 & 6.12 & 2.38 \\
\hline 54 & $\begin{array}{l}\text { Exhibit physical strength and fitness consistent with the requirements of professional } \\
\text { practice }\end{array}$ & 8.03 & 1.77 & 7.21 & 1.93 & 6.47 & 2.36 \\
\hline 55 & Able to provide leadership, mentoring and supervision skills & 8.61 & 1.33 & 6.49 & 1.82 & 4.88 & 2.50 \\
\hline 56 & Trustworthy & 8.95 & 1.20 & 7.23 & 1.87 & 5.65 & 2.71 \\
\hline 57 & Practice within an approved scope of practice & 9.12 & 1.13 & 8.04 & 1.91 & 7.29 & 2.57 \\
\hline 58 & Develop and maintain personal health and wellbeing strategies & 8.29 & 1.64 & 7.41 & 1.94 & 6.87 & 2.45 \\
\hline 59 & $\begin{array}{l}\text { Respond to changes in the provision of healthcare due to evolving community } \\
\text { expectations }\end{array}$ & 7.84 & 1.96 & 6.65 & 2.08 & 5.87 & 2.54 \\
\hline 60 & Understand the role of paramedic care within the broader healthcare system & 8.57 & 1.53 & 7.15 & 2.00 & 6.28 & 2.62 \\
\hline 61 & Embrace social responsibility & 8.29 & 1.52 & 7.33 & 1.95 & 6.91 & 2.41 \\
\hline
\end{tabular}

Abbreviation: EMT, Emergency Medical Technician; EMT-P, EMT-Paramedic.

\section{Publish your work in this journal}

Advances in Medical Education and Practice is an international, peerreviewed, open access journal that aims to present and publish research on Medical Education covering medical, dental, nursing and allied health care professional education. The journal covers undergraduate education, postgraduate training and continuing medical education including emerging trends and innovative models linking education, research, and health care services. The manuscript management system is completely online and includes a very quick and fair peer-review system. Visit http://www.dovepress.com/testimonials.php to read real quotes from published authors. 